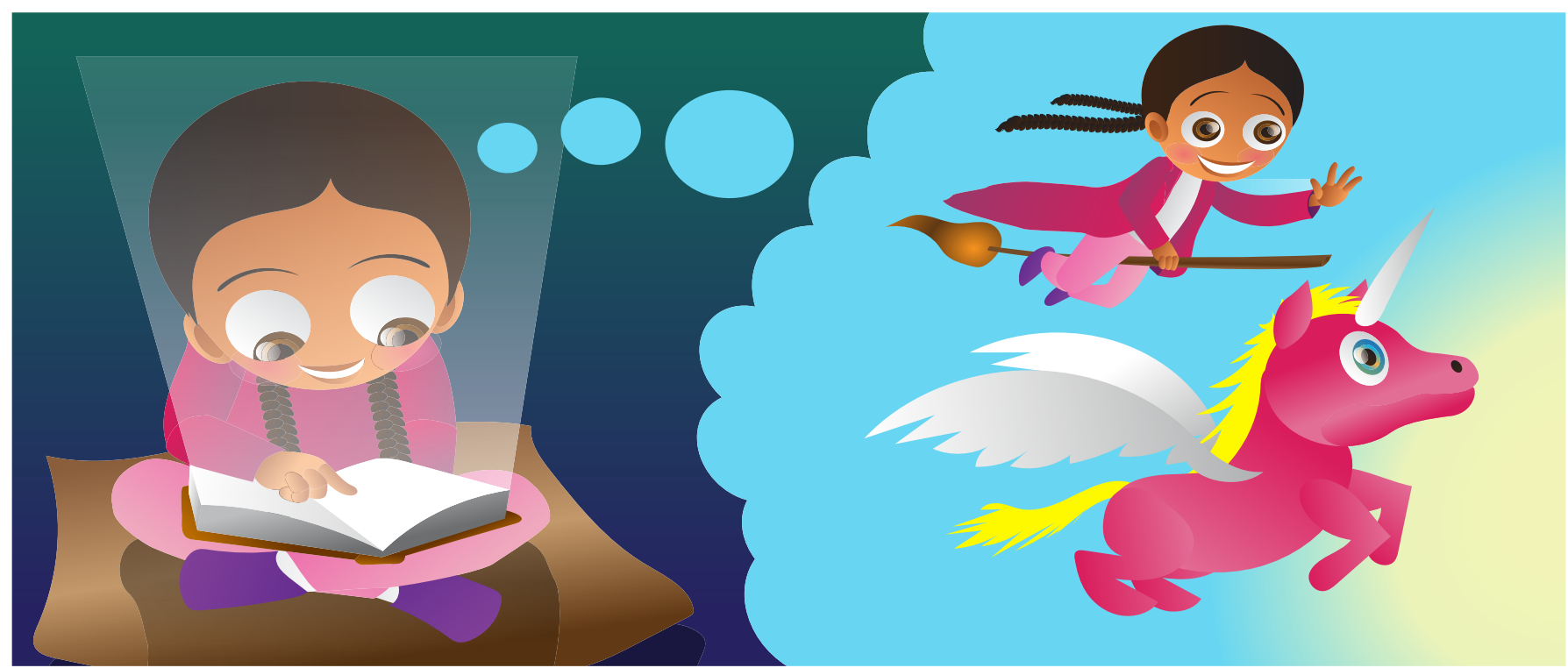

\title{
GETTING LOST IN A BOOK: THE SCIENCE OF READING COMPREHENSION
}

\section{Angela Nyhout, Agnieszka M. Fecica, Daniela K. O'Neill}

Department of Psychology, University of Waterloo, Waterloo, ON, Canada

REVIEWED BY:

KAYLEIGH 14 YEARS OLD
Have you ever felt like you got to know a character in a story, or felt like you could imagine the world she lived in? Have you ever wondered why the books we read seem to come to life in our minds? Studies from laboratories around the world are beginning to unravel this mystery. These studies show that when we read stories, our minds actually act like they are participating in the events in the story. This can make us feel like we can see what the characters see and feel what the characters feel. These findings help to tell us why people love reading fictional stories so much. The findings may also help us to find new ways to teach children who are having difficulty with reading.

"She was lost in her book," "He couldn't put the book down," "I was on the edge of my seat." These are all common phrases that we may use to describe the experience we have when we read books. In the middle of a good book, we may feel as though we have left the real world behind to be swept away to Hogwarts, Middle Earth, or Wonderland. Have you ever stayed awake at night to finish a good story like the girl in Figure 1?

When you think about it, though, our favorite novels are really just a series of little black shapes on a page, much like the text you are reading in this article. 


\section{FIGURE}

Have you ever stayed awake at night because you could not put your book down?

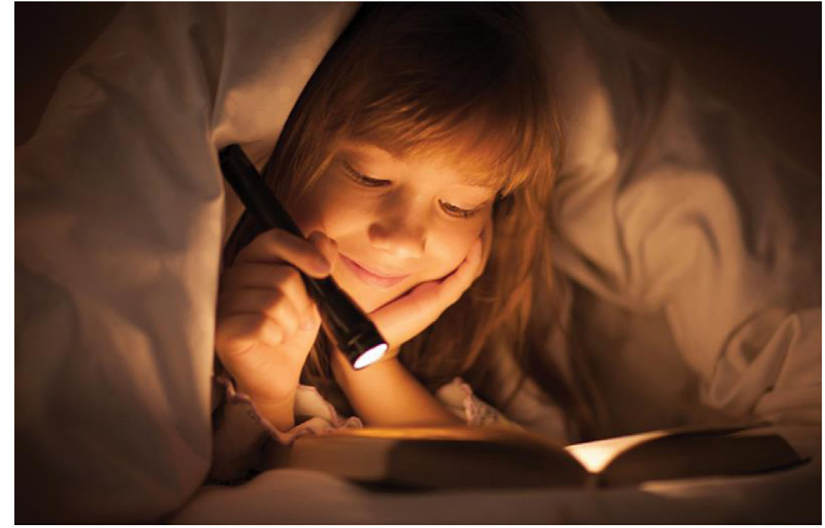

FIGURE 1

So what happens to bring stories to life in our minds? How do our minds use the letters on the page to let us step into the shoes of our favorite characters and experience the events in a story?

Recent research in psychology and neuroscience is beginning to unravel the fascinating process of reading comprehension. Reading comprehension is how we understand the meaning of the words and sentences we are reading, and it is what helps make stories come to life in our minds. Studies with both adults and children are beginning to show us that the reason we sometimes feel like we have stepped into the shoes of a story character is because our minds really do pretend that we are actually participating in the story. This is something that scientists refer to as mental simulation [1]. Just like a flight simulator allows training pilots to practice flying a plane, stories seem to be a life simulator, allowing our minds to pretend they are doing all sorts of interesting activities. Let us take a look at some of these studies; we think you will find the results very cool!

\section{PERCEPTUAL SIMULATION: SEEING WITH A CHARACTER}

Perceptual simulation is our minds' ability to copy the experiences of our senses, such as images, sounds, and tastes.

When we talk about reading, we often talk about "visualizing" the characters and settings in a story. The ability to visualize what is read is a very difficult thing to measure, because there is no way to capture a photo of what a person is imagining in their mind. Instead, scientists have come up with clever ways to tell whether people in their studies are just storing the words from a story in their mind, or if they are creating a mental image or perceptual simulation of what they are reading about. In one set of studies, scientists presented the participants in their study with sentences like "The ranger saw the bird in the sky" and "The ranger saw the bird in the nest [2]." 
Before we even explain what is the different between these two sentences, you, like the participants in the study, may be thinking about the birds in the two sentences very differently. In the first sentence, The ranger saw the bird in the sky, the bird is flying, so its wings should be outstretched. In the second sentence, The ranger saw the bird in the nest, the bird is sitting, so its wings should be tucked against its body. Participants in the study would read the sentences on a computer screen, and would then see an image on the screen that either matched (like reading The ranger saw the bird in the sky and seeing the image in Figure 2A) or did not match (like reading The ranger saw the bird in the sky and seeing the image in Figure 2B). People would click a button faster when the sentence and image matched than when they did not match. Recently, this same study was done with children and teenagers between the ages of 7 and 13, and the scientists found the same results [3]. Notice that there is nothing in the sentence that tells you or the participants in the study how the bird should look - both sentences simply say, "the bird." So, when people are faster to respond to the matching image, we can conclude it is because of perceptual simulation.

In a similar study, scientists tested whether participants would not only create a mental image but also simulate the visibility of an image [4]. Before we explain this study, first imagine yourself skiing through a forest. You are wearing a pair of goggles to keep the snow out of your eyes. You are getting warm and your goggles are starting to fog up. You see something through the trees in the distance. You cannot quite tell, but it looks like a moose! You pull of your goggles and you see that it really is a big, majestic moose. The scientists tested this same type of scenario. They presented their participants with a sentence like, Through the fogged goggles, the ranger could hardly identify the moose. They then showed them either a clear picture of a moose, as in Figure 3A, or a blurry picture of a moose, as in Figure 3B. Can you guess which picture the participants were faster to respond to? Like the study before, this suggests that, as readers, we simulate aspects of a scene that

FIGURE 2

When you read the sentence, "The ranger saw the bird in the sky," which picture is closer to how you imagined it, the flying bird (A) or the sitting bird (B)?

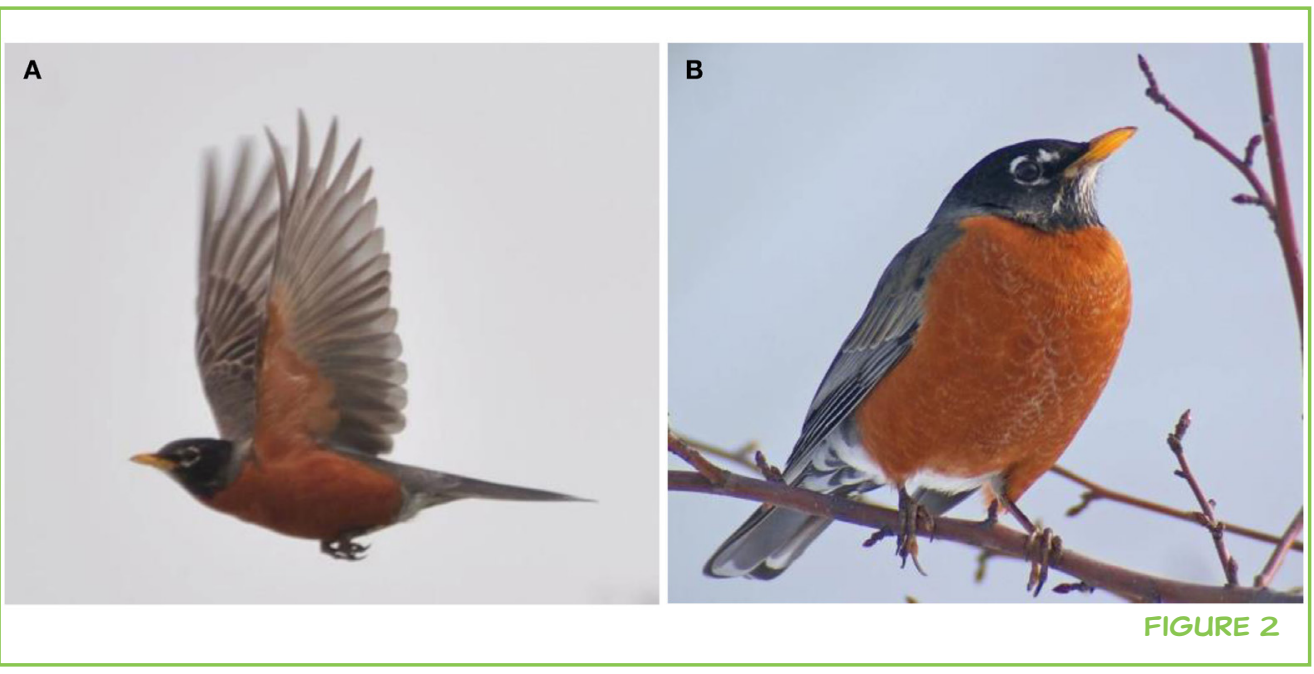


FIGURE 3

When you read the sentence, "Through the fogged goggles, the ranger could hardly identify the moose," which picture is closer to how you imagined it, $(\mathbf{A})$ or $(\mathbf{B})$ ?

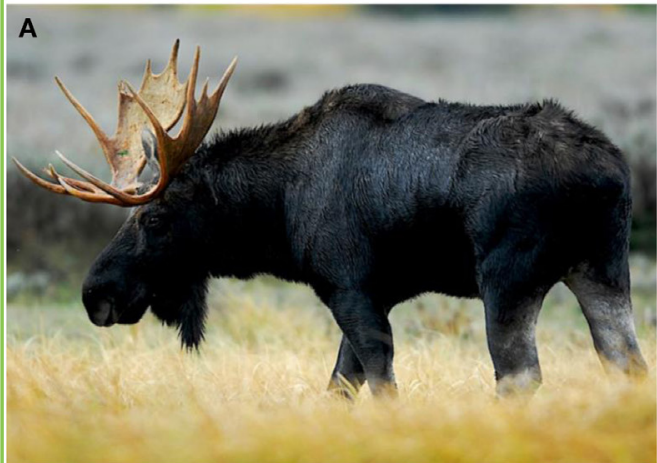

B

are not described in the words on the page. We elaborate by adding details and features that would be present if we were actually involved in the scene in real life. Impressive, isn't it?

The studies we have described so far have involved only computers that present sentences and images, and that record how long it takes participants to respond. Other studies have used more sophisticated (and expensive) machinery that is able to provide images of activity in the brain when people are reading [5]. Researchers conducting these studies have found that when participants read about, for example, a character picking up an object, the area of the brain that is involved in grasping objects is activated. When they read about kicking, the area of the brain that controls foot motions is activated! Of course, this is not a full activation, or you would be picking up or kicking things as you read. But as you read a story, some kind of activation in these brain areas is happening. It will take more studies for us to understand exactly what this activation is.

\section{TEMPORAL SIMULATION: PASSING TIME WITH A CHARACTER}

We now know that there is good evidence that people create perceptual simulations when they read. What other types of simulation might take place when we read?

Temporal simulation is our minds' ability to simulate the duration, or amount of time an activity takes. Could it be possible that people read more quickly when a character is moving quickly, compared to when they are moving slowly?

Studies from our laboratory with children aged 3-5 years have found this very thing [6]. The children in these studies were too young to read, so they listened to stories on a computer instead. The children heard one sentence at a time, and were able to click through the story at their own pace. In one study, children listened to a story in which a character was watching activities in a park as she walked by or was driven by. When you are 
walking somewhere, you of course pass by scenery more slowly (as shown in Figure 4A) than when you are being driven by (as shown in Figure 4B). Children in our study were not shown any pictures, but they clicked through these sentences more quickly when the character was being driven by.

Another way of measuring what people are doing when listening to or reading a story is through eye tracking. Scientists can place some equipment on a participant's head that allows them to track the eye movements the participant makes during a task. In a clever study, a group of scientists presented participants with sentences that included verbs that described either fast movements, such as dash, or slow movements, such as dawdle [7]. Although they were listening to the sentence, the participants also viewed a picture that showed a character and the object he was moving toward, with a path in between them. Participants eyes traced along the path more quickly when they heard verbs like dash and run than when they heard verbs like dawdle or stagger.

\section{EMOTIONAL SIMULATION: THINKING AND FEELING WITH A CHARACTER}

When you think about your experience reading your favorite book, what do you remember most? For many of us, it may be the emotions we felt when we read different parts of the story. Perhaps you felt nervous during a suspenseful part of the book, and sad during another.

Emotional simulation is our minds' ability to infer, or figure out, a character's emotional reaction to events in a story, and to feel this emotion ourselves.

Just like participants in the other study were faster to recognize images of a bird with outstretched wings when they heard a sentence like The ranger saw the bird in the sky, we might expect that readers may also be faster to recognize emotion words that match what the character is likely feeling. In one study, participants heard a story about a boy named Arthur [8]. In the story, a classmate who Arthur has a crush on comes up to him and asks him if he will

\section{FIGURE 4}

These images show the view a person may have when walking $(\mathbf{A})$ or being driven by a park (B). Based on research from our laboratory, we know that children simulate this experience and imagine passing by a park faster when a character is being driven compared to walking.
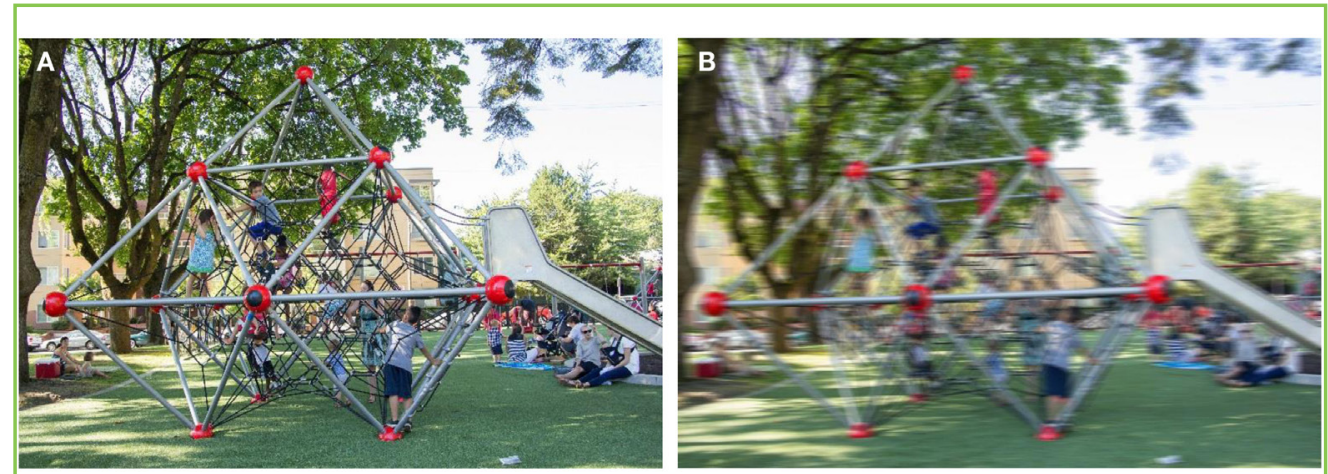

FIGURE 4 
teach her how to play tennis. Arthur is not sure if she is interested in him, or if she is just looking for a way to get into the tennis club. He is not even sure if the girl will show up. After reading the first part of the story, participants would see one of two sentences: Arthur felt quite insecure or Arthur felt quite flattered. Which sentence do you think they were faster to click the button in response to? Participants in this study were faster to recognize the emotion that matched the situation (insecure) than the one that did not match (flattered). The story describes a situation in which Arthur feels uncertain and insecure, but we have to infer these emotions and maybe even simulate them.

In other studies with adults, researchers gave participants stories to read and asked them to report their emotion or mood during or after reading the story [9]. The type of story they read influenced the way they felt. For example, participants reported feeling more negative emotions after reading a story about a character who felt fear [10]. This was especially the case if the story was written in the second-person (with you as the main character) or if the participants were asked to imagine they were the character.

In another study from our laboratory [6], 3- to 5-year-old children listened to stories about a character who was getting ready to go somewhere he was either really excited about or was dreading (see Figures 5A,B). Children did not see any pictures, but clicked through sentences describing the character getting ready (for example, changing his clothes, cleaning up toys) more quickly when the character was getting ready to go somewhere he was really excited about. They clicked through these sentences more slowly when the character was going somewhere he was dreading. This study tells us that young children are able to step into the shoes of the character and share the character's feelings.

\section{CONCLUSION}

Reading a book and getting swept into another world is such a natural experience, that often we do not take the time to think about why we can get so caught up in a story. Up until recently, the way our minds process stories was

\section{FIGURE 5}

One of these girls $(\mathbf{A})$ is much more excited to go somewhere than the other (B). Studies from our laboratory show that children processed sentences faster when they were hearing about the girl who was excited to get ready.

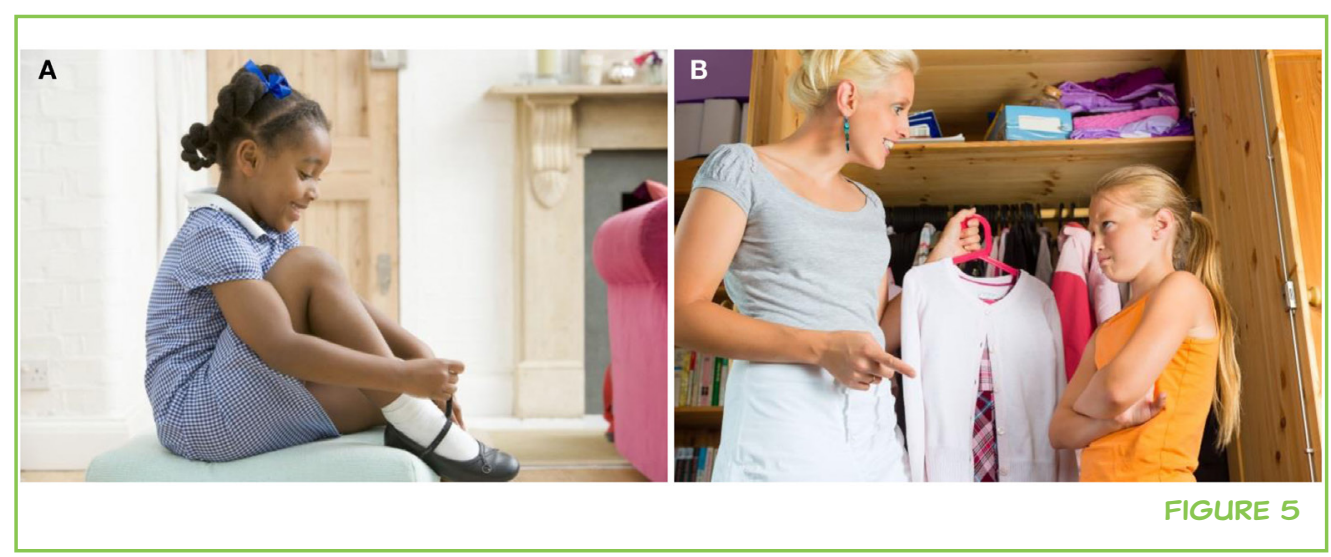


somewhat of a mystery. The research findings we have described and other new research findings in the fields of psychology and neuroscience are beginning to tell the tale of what our minds do when we read or listen to a story. More and more research is showing us that when we read a story, our minds act as if we are actually experiencing the events in the story, although safely and from the comfort of our favorite chair!

In new research from our laboratory and others [11], we are also beginning to find that difficulty creating these mental simulations is related to with more difficulty understanding and following stories that are longer and more detailed. So, for some children, not being able to see the stories in their minds may make it harder for them to keep track of everything that is going on and where, when and why it is going on. This means that this research is important, not only because it tells us something interesting about how our minds work but also because the findings could someday help teachers and parents to find new ways to help children who are having difficulty with reading.

\section{REFERENCES}

1. Mar, R. A., and Oatley, K. 2008. The function of fiction is the abstraction and simulation of social experience. Perspect. Psychol. Sci. 3:173-192. doi: 10.1111/j.1745-6924.2008.00073.x

2. Zwaan, R. A., Stanfield, R. A., and Yaxley, R. H. 2002. Language comprehenders mentally represent the shapes of objects. Psychol. Sci. 13:168-171. doi: 10.1111/1467-9280.00430

3. Engelen, J. A. A., Bouwmeester, S., de Bruin, A. B. H., and Zwaan, R. A. 2011. Perceptual simulation in developing language comprehension. J. Exp. Child Psychol. 110:659-675. doi: 10.1016/j.jecp.2011.06.009

4. Yaxley, R. H., and Zwaan, R. A. 2007. Simulating visibility during language comprehension. Cognition 105:229-236. doi: 10.1016/j.cognition.2006.09.003

5. Speer, N. K., Reynolds, J. R., Swallow, K. M., and Zacks, J. M. 2009. Reading stories activates neural representations of visual and motor experiences. Psychol. Sci. 20:989-999. doi: 10.1111/j.1467-9280.2009.02397.x

6. Fecica, A. M., and O'Neill, D. K. 2010. A step at a time: preliterate children's simulation of narrative movement during story comprehension. Cognition 116:368-381. doi: 10.1016/j.cognition.2010.05.014

7. Lindsay, S., Scheepers, C., and Kamide, Y. 2013. To dash or to dawdle: verbassociated speed of motion influences eye movements during spoken sentence comprehension. PLoS ONE 8:e67187. doi: 10.1371/journal.pone.0067187

8. de Vega, M., Lyon, I., and Diaz, J. M. 1996. The representation of changing emotions in reading comprehension. Cogn. Emot. 10:303-21. doi: 10.1080/026999396380268

9. Cupchik, G. C., Oatley, K., and Vorderer, P. 1998. Emotional effects of reading excerpts from short stories by James Joyce. Poetics 25:363-377. doi: 10.1016/ S0304-422X(98)90007-9 
10. Brunyé, T. T., Ditman, T., Mahoney, C. R., and Taylor, H. A. 2011. Better you than I: perspectives and emotion simulation during narrative comprehension. J. Cogn. Psychol. 23:659-666. doi: 10.1080/20445911.2011.559160

11. Barnes, M. A., Raghubar, K. P., Faulkner, H., and Denton, C. A. 2014. The construction of visual-spatial situation models in children's reading and their relation to reading comprehension. J. Exp. Child Psychol. 119:101-111. doi: 10.1016/j. jecp.2013.10.011

SUBMITTED: 14 April 2015; ACCEPTED: 20 October 2015;

PUBLISHED ONLINE: 06 November 2015.

EDITED BY: Sabine Kastner, Princeton University, USA

CITATION: Nyhout A, Fecica AM and O'Neill DK (2015) Getting lost in a book: the science of reading comprehension. Front. Young Minds 3:15. doi:10.3389/frym.2015.00015

COPYRIGHT @ 2015 Nyhout, Fecica and O'Neill. This is an open-access article distributed under the terms of the Creative Commons Attribution License (CC BY). The use, distribution or reproduction in other forums is permitted, provided the original author(s) or licensor are credited and that the original publication in this journal is cited, in accordance with accepted academic practice. No use, distribution or reproduction is permitted which does not comply with these terms.

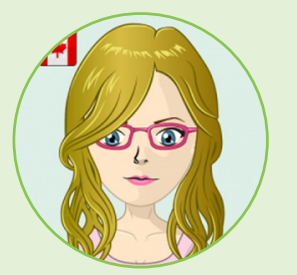

\section{REVIEWED BY}

\section{KAYLEIGH, 14 YEARS OLD}

I am 14 years old and compete competitively in Highland Dancing and Cheerleading and was selected to represent my province at the Canadian Highland Dancing championships. I like learning about animals and enjoy doing science experiments. I love swimming, riding my bike and hanging out with my friends. And eating tacos.

\section{AUTHORS}

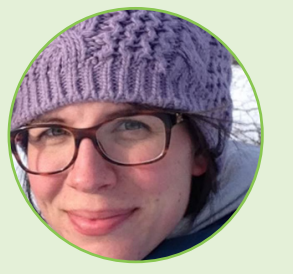

\section{ANGELA NYHOUT}

I am a researcher who studies children's language and learning. Like all researchers, I ask questions and look for answers. Some of the questions that I am most interested in are: How do children learn to understand language about things that are far away or have never happened (for example, in stories)? How do children learn how to read? How do children (and grown-ups) imagine and visualize what they are reading about? Why do some children have trouble learning how to read? How can books be used to teach children new things about the world (for example, about rainforests)? When I am not doing research, I like to hang out with my husband and our 3 cats. I also like playing ultimate frisbee and coaching athletes with Special Olympics Ontario. I like visiting big cities, and camping in the wilderness. I love reading both fiction and non-fiction books. 


\section{AGNIESZKA M. FECICA}

I am a developmental psychologist interested in how human minds understand stories. I am especially interested in our ability to step into the shoes of different characters and share their feelings, thoughts, and perceptions. I enjoy reading books and love listening to really great and elaborate stories. I also enjoy traveling, watching comedies, and spending time with my two little boys - who tell the silliest stories.

\section{DANIELA K. O'NEILL}

I am a developmental psychologist, which is someone who studies how humans develop different abilities and skills and how these changes from infancy to adulthood. In my lab at the University of Waterloo, where parents and children take part in our studies, we are always trying to learn more about how toddlers begin to take part in, and understand, conversations and stories and how these abilities quickly get more sophisticated over the next few years. In my free time, my husband, daughter and I love visiting family and friends, watching movies, reading, exploring our community, and going skiing. 